\title{
A simulation model of competition between winter wheat and Avena fatua for light
}

\author{
By S E WEAVER*, M J KROPFF ${ }^{1}$ and R COUSENS ${ }^{2}$ \\ Agriculture Canada, Research Station, Harrow, Ontario, Canada NOR $1 G 0$ \\ ${ }^{1}$ International Rice Research Institute, Agroecology Unit, P O B 933, 1099 Manila, \\ Phillippines, and Department of Theoretical Production Ecology, Agricultural \\ University, P O Box 430, 6700 AK Wageningen, The Netherlands \\ ${ }^{2}$ School of Crop Sciences, University of Sydney, New South Wales 2006, Australia \\ (Accepted 12 October 1993)
}

\begin{abstract}
Summary
An eco-physiological simulation model of competition between Avena fatua and winter wheat (Triticum aestivum $\mathrm{cv}$. Avalon) for light was parameterised and tested. The model simulates growth of each species, in kg dry matter ha ${ }^{-1}$ day $^{-1}$, from sowing to maturity as a function of irradiance, temperature and various species characteristics. Parameter values were derived from the literature and from field experiments with each species grown in monoculture. Model performance was tested against 50:50 mixtures of the two species grown at two sites in southern England. Sensitivity analyses were performed in which the canopy height of each species and the density and time of emergence of $A$. fatua were systematically varied while all other parameters were left unchanged. Accurate simulations of growth in mixtures depended upon an accurate description of the canopy height of each species throughout the growing season. Model predictions of winter wheat yield losses in relation to $A$. fatua density and time of emergence showed good agreement with previously published data.
\end{abstract}

Key words: Avena fatua, wild-oat, Triticum aestivum, winter wheat, simulation model, competition

\section{Introduction}

Avena fatua $\mathrm{L}$. is a weed of major economic importance, particularly in cereal crops (Holm, Plucknett, Pancho \& Herberger, 1977; Wilson \& Peters, 1982; Carlson \& Hill, 1985; Martin, Cullis \& McNamara, 1987). The ability of $A$. fatua to reduce crop yields has been attributed to its height and leaf area distribution which reduce light penetration to the crop canopy (Cudney, Jordan \& Hall, 1991; Morishita, Thill \& Hammel, 1991; Rooney, 1991), its high net assimilation rate during the early growth stages (Thurston, 1959), and to the role of its extensive root system in depriving the crop of water and nutrients when these resources are limiting (Pavlychenko \& Harrington, 1935; Carlson \& Hill, 1986). The impact of $A$. fatua on crop yields has been shown to vary with environmental conditions, weed and crop density (Cousens, Peters \& Marshall, 1984; Martin et al., 1987), relative time of emergence (Peters \& Wilson, 1983), and morphological traits of the crop and weed (Balyan, Malik, Panwar \& Singh, 1991; Rooney, 1991). Cousens et al. (1991) suggested

*Corresponding author

(C) 1994 Association of Applied Biologists 
that the relative timing of canopy development of the crop and weed between stem elongation and anthesis, which is strongly influenced by environmental conditions, is crucial to the outcome of competition. The use of a computer simulation model allows one to investigate the influence of various factors on the process of competition, and to make predictions about the crop yield expected under a given set of circumstances which can then be tested in the field.

Eco-physiological simulation models have been developed for both crop and weed species grown in monoculture (Penning de Vries \& van Laar, 1982; Weir, Bragg, Porter \& Rayner, 1984; Spitters, van Keulen \& van Kraalingen, 1989). Simulation models of weed-crop competition for light were first introduced by Spitters \& Aerts (1983), and further developed in subsequent studies to include competition for water and nutrients (Kropff, 1988; Spitters, 1989; Graf et al., 1990: Wilkerson, Jones, Coble \& Gunsolus, 1990: Kropff \& Spitters, 1992). The present study describes the parameterisation and testing of a simulation model of competition between $A$. fatua and winter wheat for light when water and nutrients are not limiting, based on the model of Spitters (1989) and Kropff \& Spitters (1992). Weaver, Kropff \& Cousens (1993) previously parameterised and tested the model for monocultures of $A$. fatua. Here, we add winter wheat parameters to the model, test the performance of the model against experimental monocultures of winter wheat and mixtures of winter wheat and $A$. fatua, and perform sensitivity analyses.

\section{Materials and Methods}

\section{Model description}

A detailed description of the basic structure of the model and a list of parameters were given in Kropff \& Spitters (1992). The model simulates growth of each species from sowing

Table 1. Parameter values used in the model for winter wheat growth

\section{Description}

Light interception and photosynthesis:

Extinction coefficient for PAR

Initial light use efficiency

Maximum photosynthetic rate of individual leaves

Maintenance respiration coefficients:

Leaves

Stems

Roots

Reproductive organs

Carbohydrate conversion efficiency:

Leaves

Stems

Roots

Reproductive organs

Dry matter partitioned to the leaves: Leaf area growth prior to canopy closure: Specific leaf area: Canopy height:
Value

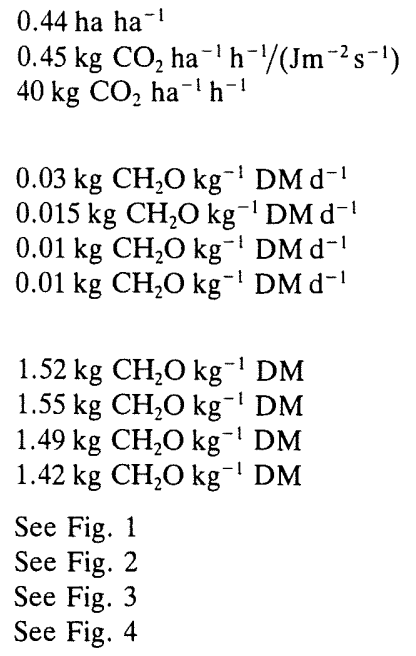

${ }^{a}$ References: Gallagher \& Biscoe, 1978; van Heemst, 1988; Spitters et al., 1989 (see text). 
to maturity with a time step of one day. Dry matter accumulation of each species is simulated on a per unit area basis $\left(\mathrm{kg} \mathrm{ha}^{-1} \mathrm{day}^{-1}\right)$ as a function of irradiance, temperature and various species characteristics. The model simulates competition for light by calculating the amount of incoming radiation absorbed by each species, based upon their leaf area indices, vertical distribution of leaf area, and light extinction coefficients. The canopy is divided into a number of horizontal layers, and the proportion of leaf area of each species in that layer is determined from the height and leaf area distribution of that species. For each species, the horizontal distribution of leaf area is assumed to be homogeneous, and the vertical distribution of leaf area is assumed to be parabolic in shape. Instantaneous rates of $\mathrm{CO}_{2}$ assimilation are calculated at different depths within the canopy, at several times during the day, based on the amount of light absorbed and the photosynthetic rate of individual leaves, and are then integrated over the height of the canopy and over the day. Net daily growth rates of each species are obtained by converting the assimilated $\mathrm{CO}_{2}$ into carbohydrates $\left(\mathrm{CH}_{2} \mathrm{O}\right)$ and subtracting the amounts used for growth and maintenance respiration. The distribution of dry matter to the various plant organs and the growth in canopy height of each species are simulated as empirical functions of developmental stage. Phenological development is simulated as an empirical function of accumulated degree days modified by photoperiod (Weir et al., 1984). Soil moisture and nutrients were assumed to be adequately supplied for this application. The effects of insects and diseases and interactions other than competition, such as allelopathy, are not accounted for in the model. A FORTRAN version of the model and a complete list of variables are available from $\mathrm{M} \mathrm{J}$ Kropff upon request.

Required inputs to the model include daily weather data (maximum and minimum temperature, global radiation, rainfall), site latitude, sowing density, date of sowing and

Table 2. Parameter values used in the model for phenological development of winter wheat

\begin{tabular}{|c|c|c|c|}
\hline Growth Stage & $\begin{array}{c}\text { Base } \\
\text { Temperature } \\
\left({ }^{\circ} \mathrm{C}\right)\end{array}$ & $\begin{array}{c}\text { Base } \\
\text { Photoperiod } \\
\text { (h) }\end{array}$ & $\begin{array}{c}\text { Accumulated } \\
\text { degree days } \\
\left({ }^{\circ} \mathrm{C} \text { days }\right)\end{array}$ \\
\hline
\end{tabular}

Phenological development:

Sowing to emergence

Emergence to double ridge

Double ridge to anthesis

Anthesis to maturity

\section{1}

$\begin{array}{lll}1 & - & 148^{\mathrm{a}} \\ 1 & 7 & 284^{\mathrm{b}} \\ 1 & 7 & 600^{\mathrm{c}} \\ 9 & - & 350^{\mathrm{a}}\end{array}$

a Thermal time over $\mathrm{i}$ days calculated as: $\sum_{1}^{i}\left(\frac{T_{\max }+T_{\min }}{2}-T_{B a s e}\right)$ where $T_{\max }, \mathrm{T}_{\min }$ and

$\mathrm{T}_{\text {base }}$ are the daily maximum and minimum temperatures and the base temperature, respectively.

${ }^{\mathrm{b}}$ Thermal time modified by a photoperiod factor (FP) and a vernalization factor (FV):

$$
F P=\frac{P_{i}-P_{\text {Base }}}{24-P_{\text {Base }}}, 0 \leq F P \leq 1
$$

where $\mathrm{P}_{i}$ and $\mathrm{P}_{\text {base }}$ are the photoperiod on day ${ }_{i}$ and the base photoperiod, respectively.

$$
F V=\frac{V_{\text {sum }}-V_{\text {base }}}{\mathrm{V}_{\text {sat }}-V_{\text {base }}}, 0 \leq F V \leq 1
$$

where $V_{\text {sum }}$ represents cumulative vernalised degree days, and $V_{\text {sat }}$ and $V_{\text {base }}$ are 33 and 8 vernal degree days, respectively, as described by Weir et al. (1984). The daily increment in thermal time is multiplied by both FP and FV.

' Thermal time modified by a photoperiod factor (FP) only, with FP as in (b). 
biological parameters specific to the species. Parameter values used in the model for $A$. fatua are listed in Weaver et al. (1993). They were derived both from the literature and from field experiments using seven different dates of sowing over 3 years. We intended to derive parameter values for winter wheat entirely from the literature and existing models, and to use experimental data on winter wheat grown in monoculture and in mixture with A. fatua to test the performance of the model. However, the pattern of dry matter partitioning and the specific leaf area of the winter wheat monocultures differed from those reported in the literature, and so the experimentally derived values of these parameters were used in the model. Data from the mixtures of winter wheat and A. fatua were used only to test model performance and not for parameter derivation.

\section{Experimental design}

Winter wheat $\mathrm{cv}$. Avalon and $A$. fatua were grown in monoculture and in mixture at each of two sites: Long Ashton Research Station, southwest England, on a sandy silt loam soil ( $\mathrm{pH}$ 7.4), and Broom's Barn Experimental Station, eastern England, on a sandy loam soil (pH 7.7). The A. fatua seeds had been harvested in 1985 from a stock-bed at Begbroke Hill, Oxford, and were sieved to obtain a uniform sample in the range 1.5 to $2.0 \mathrm{~mm}$. Seeds

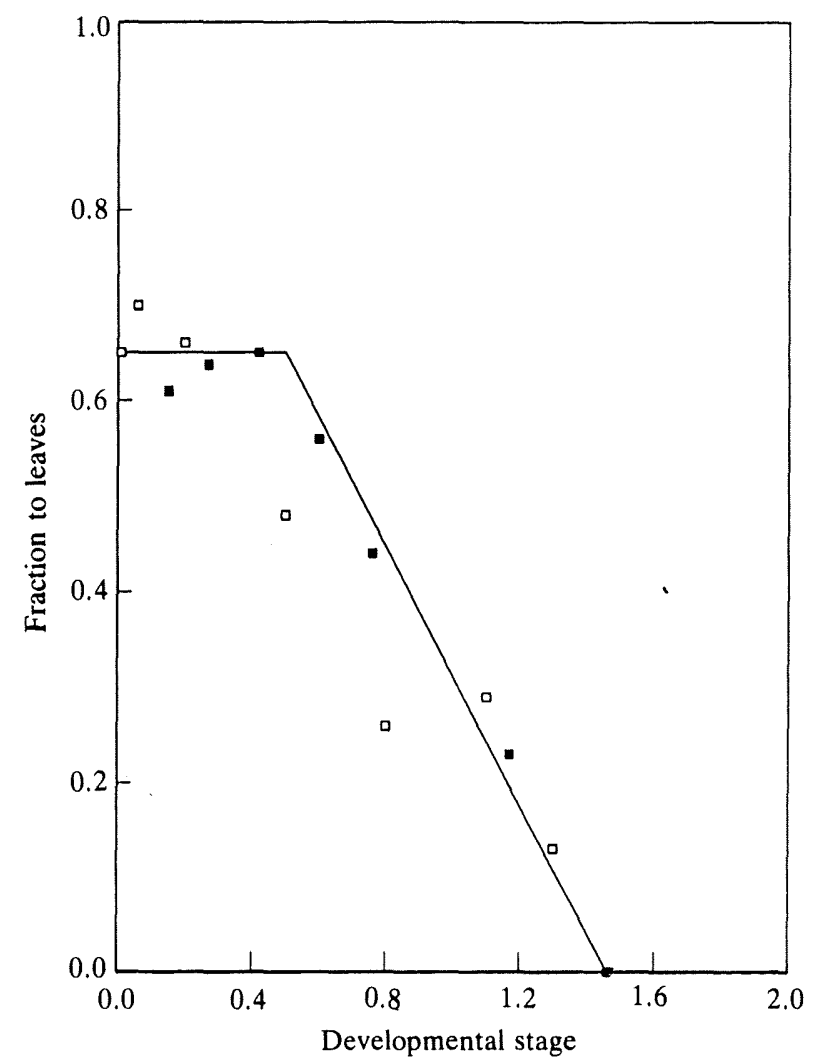

Fig. 1. The fraction of new "shoot" assimilates that are partitioned to the leaves as a function of developmental stage of winter wheat where 0 is emergence, 1 is the appearance od double ridges on the main stem and 2 is anthesis. Points represent values calculated by dividing the increment in green leaf dry weight by the increment in total "shoot" dry weight between each two subsequent harvests for the Long Ashton ( $\square$ ) and Broom's Barn (a) sowings. The solid line indicates the relationship used in the model. 
of both species were sown at a depth of $5 \mathrm{~cm}$ in a rectangular grid pattern, with $7 \mathrm{~cm}$ between rows and $5 \mathrm{~cm}$ between holes within rows. This gave a potential plant density of $286 \mathrm{~m}^{-2}$. One seed of winter wheat was sown per hole, and two seeds of $A$. fatua, with the seedlings later thinned to one per location. Gaps with no seedling were left unfilled. In mixtures, the two species were sown in alternate rows. Mean densities of monocultures after thinning were 192 and 216 plants $\mathrm{m}^{-2}$ for winter wheat, and 203 and 243 plants $\mathrm{m}^{-2}$ for $A$. fatua at Long Ashton and Broom's Barn, respectively. The mean density of each species in mixture was approximately half of that in monoculture. Planting dates were 17 October 1988 at Long Ashton and 26 October 1988 at Broom's Barn. Plots were $1.2 \mathrm{~m} \times 2.0 \mathrm{~m}$ in a randomised complete block design with four replicates. Other weeds were removed by hand. Ammonium nitrate was applied to the plots in the spring at a rate of $150 \mathrm{~kg} \mathrm{~N} \mathrm{ha}^{-1}$, and fungicides and insecticides were applied as required in order to meet the assumptions of the model that nutrients and pests did not limit plant growth (Cousens et al., 1991).

Seeds were sown in late October 1988, and plants were sampled at frequent intervals until anthesis of $A$. fatua occurred in June 1989. The plots were destroyed before the plants matured in order to prevent return of $A$. fatua seed to the field. At each harvest, canopy height was measured from the ground to the highest point on the uppermost leaf of four plants of each species from each replicate. The plants were then cut just above the crown node, and green leaf area and the dry weight of stems, green leaves and dead leaves were

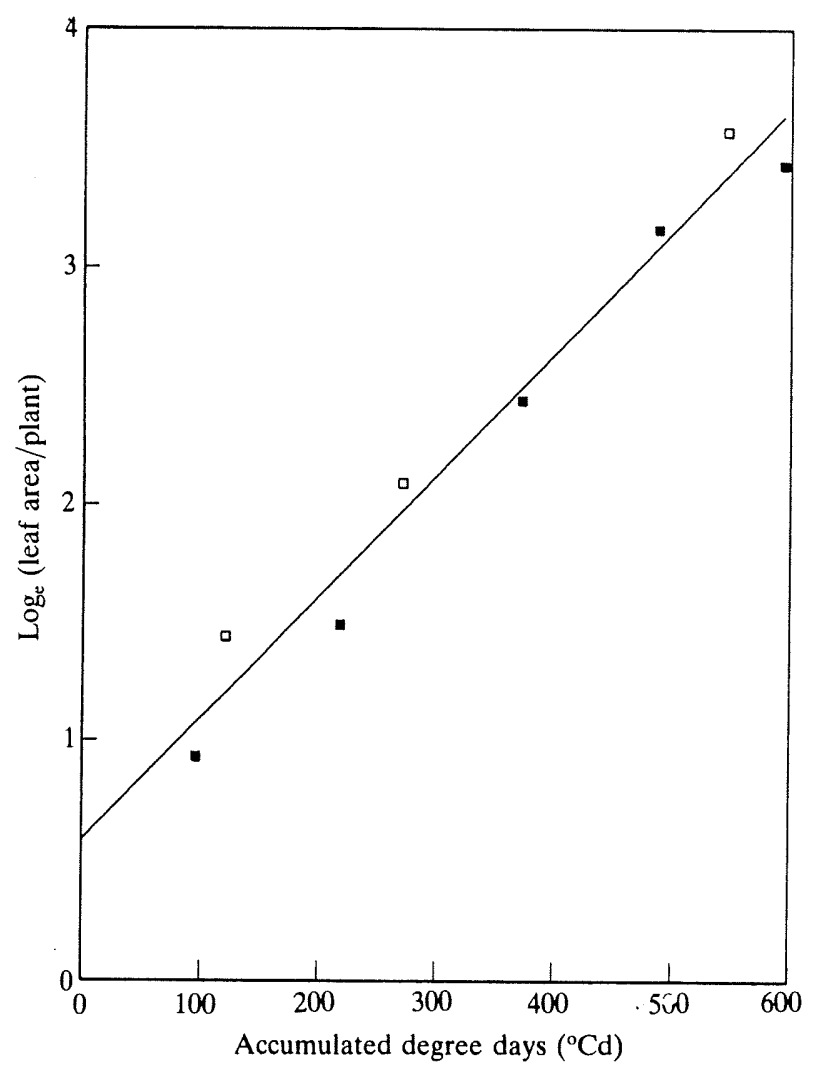

Fig. 2. The natural logarithm of leaf area per plant $\left(\mathrm{cm}^{2}\right)$ as a function of accumulated degree days see Table 2) from emergence until caopy closure (LAI = 1) for winter wheat sown in October, 1988 at Long Ashton $(\square)$ and Broom's Barn ( $\square)$. The solid line represents the fitted regression equation used in the model, $\mathrm{Y}=0.583+0.005 \times$. 


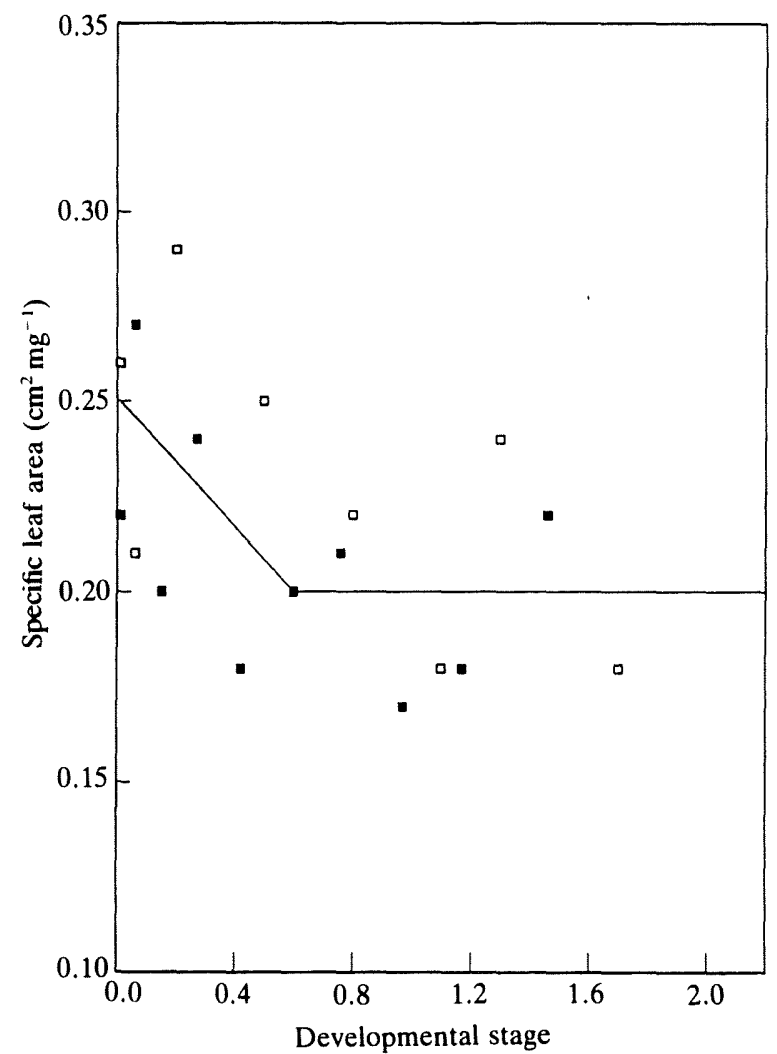

Fig. 3. Specific leaf area $\left(\mathrm{cm}^{2} \mathrm{mg}^{-1}\right)$ as a function of developmental stage for winter wheat sown in October 1988 at Long Ashton ( $\square$ ) and Broom's Barn (घ). The solid line indicates the relationship used in the model.

assessed. Sampling was conducted systematically from the ends of the plots, leaving guard rows around the outside border and between sampling dates to avoid edge effects.

\section{Estimation of parameter values for winter wheat}

\section{Photosynthesis and respiration}

Values of parameters dealing with photosynthesis and respiration (Table 1) were taken from the literature, and are identical to those used in the model for $A$. fatua (Weaver et al., 1993). The value of the extinction coefficient for photosynthetically active radiation (PAR) was reported by Gallagher \& Biscoe (1978) and used in the winter wheat simulation model of Weir et al. (1984). The initial light use efficiency and maximum rate of photosynthesis of individual leaves are values reported for winter wheat by van Heemst (1988) and Spitters et al. (1989). In the model, the maximum rate of photosynthesis remains at $40 \mathrm{~kg} \mathrm{CO}_{2} \mathrm{ha}^{-1} \mathrm{~h}^{-1}$ from emergence to anthesis, and then declines linearly to $20 \mathrm{~kg} \mathrm{CO}$ $\mathrm{ha}^{-1} \mathrm{~h}^{-1}$ at maturity, as was described for $A$. fatua (Weaver et al., 1993). Requirements for maintenance respiration are temperature sensitive (values shown in Table 1 are for $25^{\circ} \mathrm{C}$ with $\mathrm{Q}_{10}=2$; van Heemst, 1988) and decrease with plant age in proportion to the fraction of the accumulated leaf weight that is still green (Spitters et al., 1989). Assimilate require- 
ments for the conversion of carbohydrates into dry matter are values typical for cereals (van Heemst, 1988; Spitters et al., 1989).

\section{Phenological development}

The model calculates the phenological development of winter wheat by dividing the life cycle into four stages along a dimensionless scale, where 0 is emergence, 1 is the appearance of double ridges on the main stem, 2 is anthesis and 3 is maturity. Each growth stage is characterised by a base temperature, a base photoperiod (where applicable), and a required number of degree days for completion (Table 2). The base temperatures, base photoperiods and accumulated number of degree days for each growth stage are those reported by Weir et al. (1984). The periods between sowing and emergence, and anthesis and maturity, are simulated solely as a function of accumulated degree days, or thermal time. Development between emergence and anthesis depends upon both temperature and photoperiod, and so was simulated as a function of accumulated degree days modified by photoperiod and vernalisation factors similar to those used by Weir et al. (1984).

\section{Dry matter partitioning}

The partitioning of dry matter to the leaves, stems, roots and reproductive organs is treated as an empirical function of developmental stage. The daily net assimilate (the

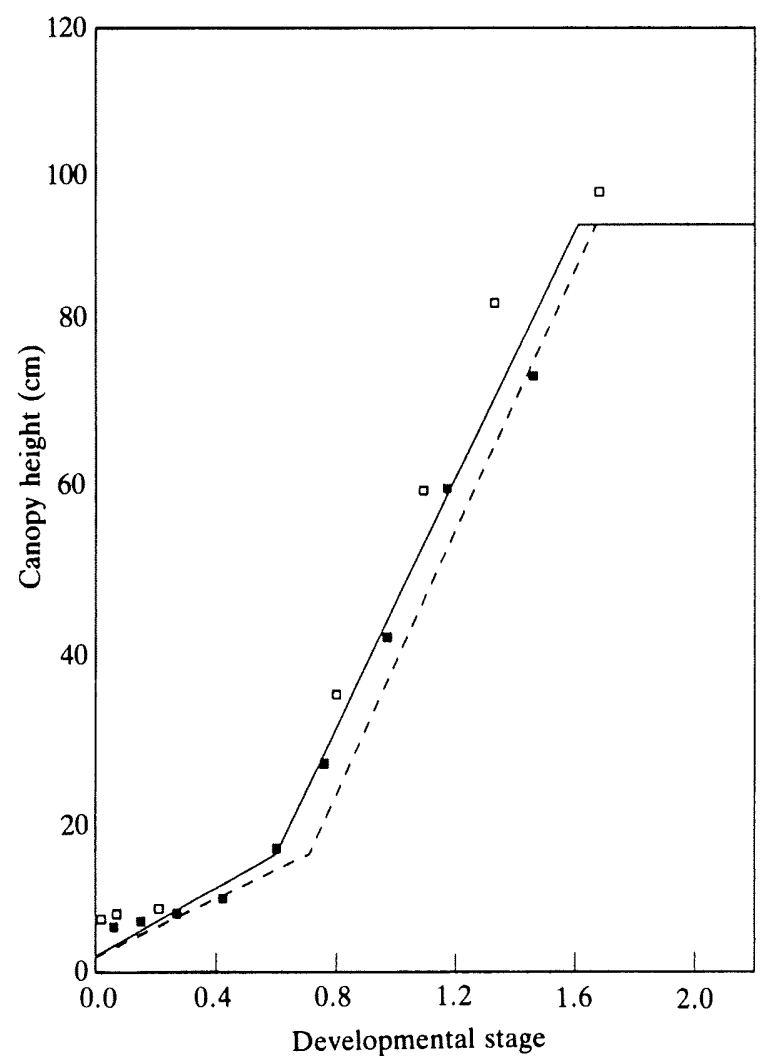

Fig. 4. Canopy height as a function of developmental stage for winter wheat sown in October 1988 at Long Ashton ( $\square$ ) and Broom's Barn ( $\square$ ). The solid line indicates the relationship used in the model. The dashed line represents the relationship used in the sensitivity analyses. 

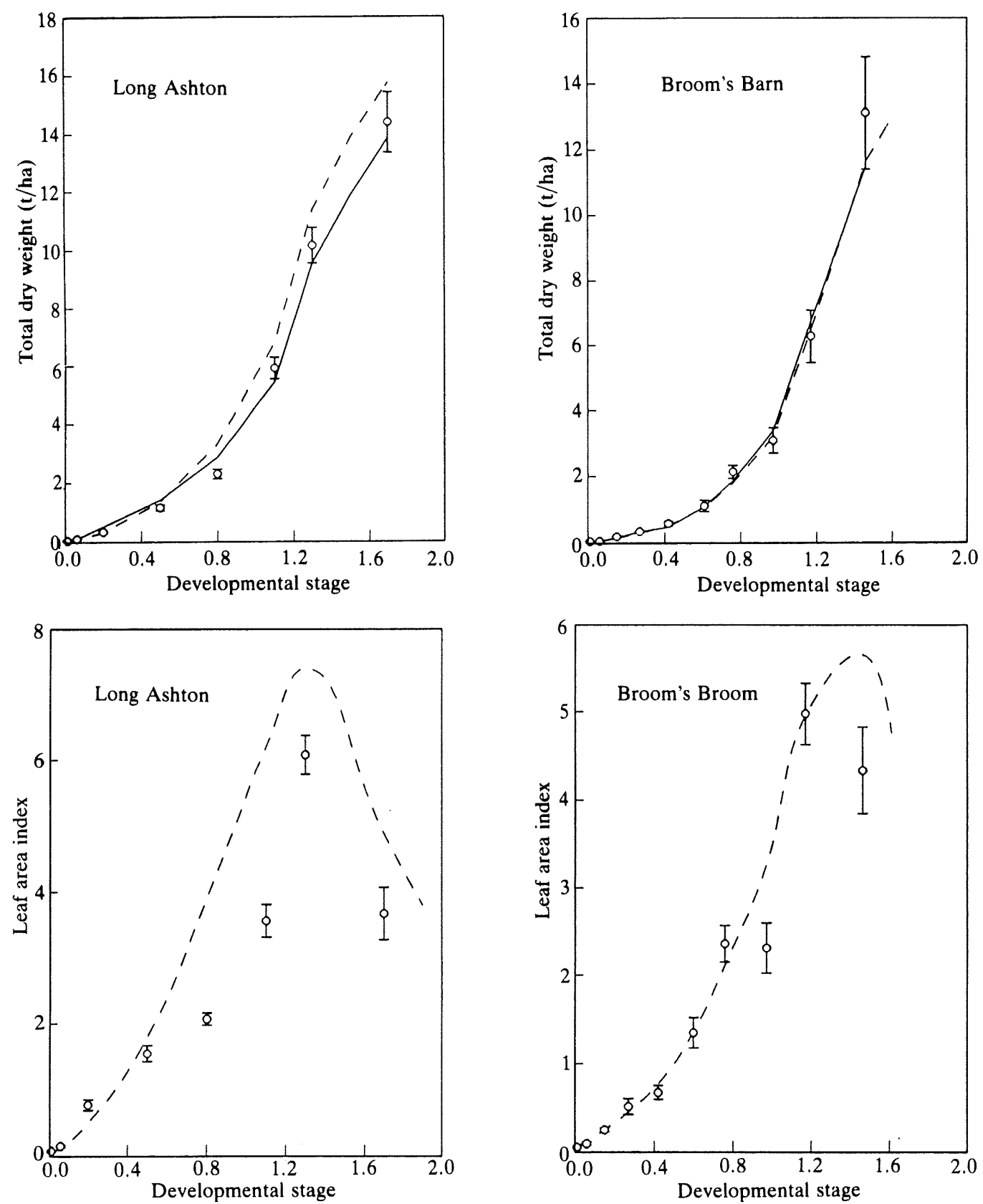

Fig. 5. Simulated (lines) and observed (0) total dry weight (above-ground) and leaf area index as a function of developmental stage for monocultures of winter wheat, sown in October, 1988 at Long Ashton and Broom's Barn. Vertical bars indicate one standard error. The solid lines represent model runs with observed LAI values as input; the dashed lines represent model runs with simulated LAI.

difference between photosynthate production and respiration) is first divided between roots and "shoots", and then the "shoot" fraction is further subdivided between leaves, stems and reproductive organs. The model assumes that the fraction of new assimilates allocated to root growth is 0.35 at emergence, declining to 0.2 at the double ridge stage and to 0.0 

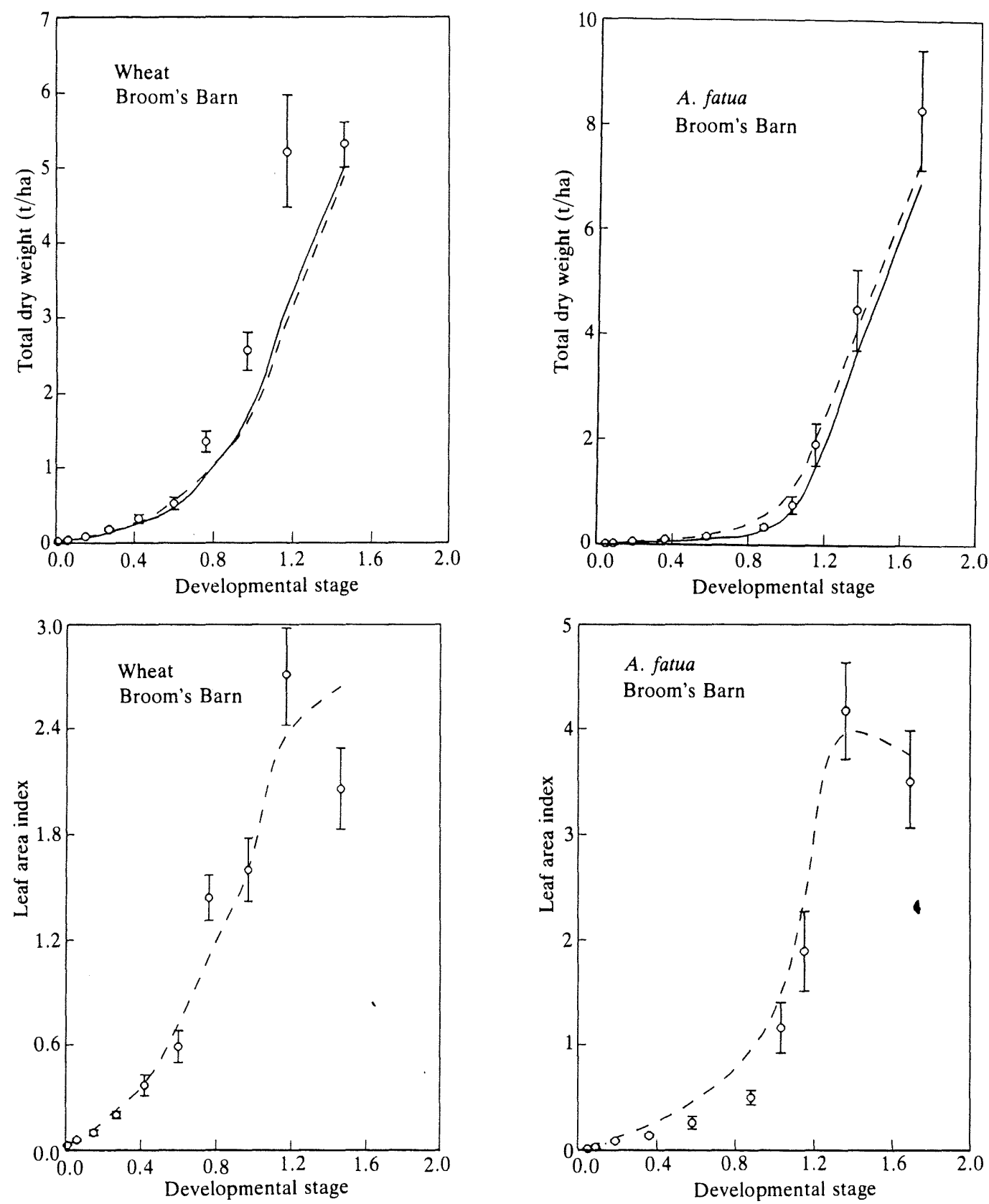

Fig. 6. Simulated (lines) and observed (0) total dry weight (above-ground) and leaf area index as a function of developmental stage for mixtures of winter wheat and Avena fatua sown in October 1988 at Broom's Barn. Vertical bars indicate one standard error. The solid lines represent model runs with observed LAI values as input; the dashed lines represent model runs with simulated LAI.

at anthesis. These values are similar to those used for winter wheat by Weir et al. (1984). Descriptions of the division of assimilates between leaves and stems from emergence to anthesis vary widely (Weir et al., 1984; Spitters et al., 1989; van Heemst, 1988). Values were therefore derived from the monoculture sowings of winter wheat at Long Ashton and 
Broom's Barn (Fig. 1). After anthesis, all new assimilates are allocated to the reproductive organs. This is a simplified simulation of dry matter partitioning which does not include a pool of assimilates for redistribution within the plant, as has been done in other studies (Weir et al., 1984; Spitters et al., 1989).

\section{Leaf area and canopy height}

Leaf area index (LAI) is used to determine the amount of light intercepted by the canopy of each species. Prior to canopy closure, leaf area per plant is simulated as an exponential function of accumulated degree days (Fig. 2), and LAI as the product of leaf area per plant and plant density. After canopy closure, LAI is simulated as the product of leaf weight per unit area and specific leaf area (SLA). Specific leaf area is an empirical function of developmental stage (Fig. 3). Although several other studies have assumed a constant SLA of $0.2 \mathrm{~cm}^{2} \mathrm{mg}^{-1}$ for winter wheat throughout the life cycle (van Heemst, 1988; Spitters $e t$ al., 1989), the relationship shown in Fig. 3, derived from the monoculture experiments, was used in the model. The relative death rate of leaves is also treated as an empirical function of developmental stage. In the model, leaf senescence was assumed to begin halfway between the double ridge stage and anthesis at the rate of $0.03 \mathrm{~kg} \mathrm{ha}^{-1} \mathrm{day}^{-1}$, and to increase to $0.04 \mathrm{~kg} \mathrm{ha}^{-1} \mathrm{day}^{-1}$ from anthesis until maturity. These values are similar to those reported for winter wheat by Spitters et al. (1989), although changes in the relative death rate due to shading or extreme temperatures are not accounted for in this version of the model.

The height of the leaf canopy is an important parameter in simulating competition between plant species, because it influences the relative share of the incoming radiation that each receives. The model treats canopy height as an empirical function of developmental stage, and neglects changes in height due to shading. The relationship between canopy height and developmental stage used in the model is a simplified description of the data obtained from the monoculture experiments (Fig. 4).

\section{Testing model performance}

Simulation runs with the model were conducted in two ways. First, the model was run using observed leaf areas from sequential harvests of each species as input, in order to evaluate the carbon balance section of the model. Secondly, the runs were repeated using the same parameter values, but also simulating the development of leaf area. The performance of the model was evaluated based on its ability to accurately simulate the growth of winter wheat and $A$. fatua in mixture, using parameters derived from the literature and from monoculture experiments. Simulations were considered accurate if they fell within one standard error of observed values. Sensitivity analyses were conducted using different canopy heights of winter wheat and different densities or times of emergence of $A$. fatua, and results were compared with general relationships derived from published field data.

\section{Results}

\section{Growth in monocultures}

The growth of winter wheat in monoculture at Long Ashton and Broom's Barn was accurately simulated by the model when observed leaf areas from sequential harvests were put into the model (Fig. 5). Leaf area growth was slightly greater at Long Ashton than at Broom's Barn. At Broom's Barn, the performance of the model when leaf areas were simulated was almost identical to that when leaf areas were input. The model overestimated 

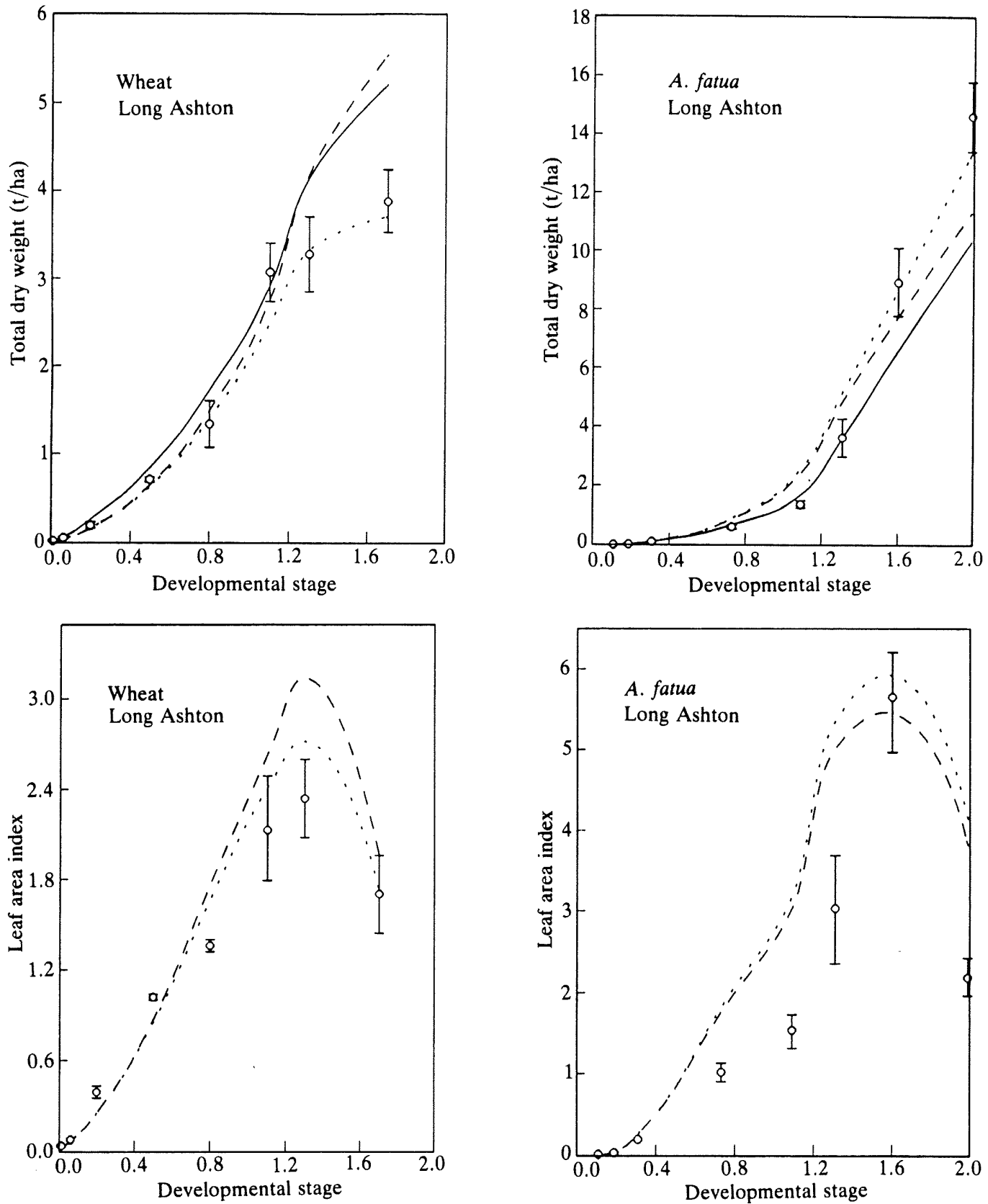

Fig. 7. Simulated (lines) and observed (0) total dry weight (above-ground) and leaf area index as a function of developmental stage for mixtures of winter wheat and Avena fatua sown in October 1988 at Long Ashton. Vertical bars indicate one standard error. The solid lines represent model runs with observed LAI values as input; the dashed lines represent model runs with simulated LAI; the dotted lines represent model runs with observed heights as input and simulated LAI.

leaf area indices of winter wheat at Long Ashton, however, which led to a slight overestimation of dry matter accumulation with simulated leaf areas.

The ability of the model to simulate growth and development of $A$. fatua in monoculture was described previously by Weaver et al. (1993). In general, the model accurately simulated 
dry matter accumulation of monocultures of $A$. fatua for seven different sowing dates over three years and two locations. However, the model underestimated above-ground biomass of $A$. fatua at the harvest just prior to anthesis for the October 1988 Long Ashton and Broom's Barn sowings, both when observed leaf areas were input and when leaf area was simulated. Monocultures of $A$. fatua attained maximum LAI values of 7 to 8 at both sites (Weaver et al., 1993), compared to maximum LAI values of 5 to 6 for winter wheat (Fig. $5)$.

\section{Growth in mixtures}

When the growth of mixtures of winter wheat and A. fatua at Broom's Barn was simulated with observed leaf areas as input, the model underestimated observed dry weights of winter wheat at three intermediate harvests, but fell within the limits of experimental error early in the growing season and at the final harvest (Fig. 6). Dry matter accumulation of $A$. fatua in mixture was underestimated at the final harvest before anthesis, as it had been in monoculture, but corresponded well with observed values at previous harvests. Leaf area development of both species was simulated accurately, and so model behaviour was similar when leaf areas were simulated. In mixture, $A$. fatua achieved a maximum LAI of approximately 4, whereas winter wheat reached an LAI of only 2.7 (Fig. 6).

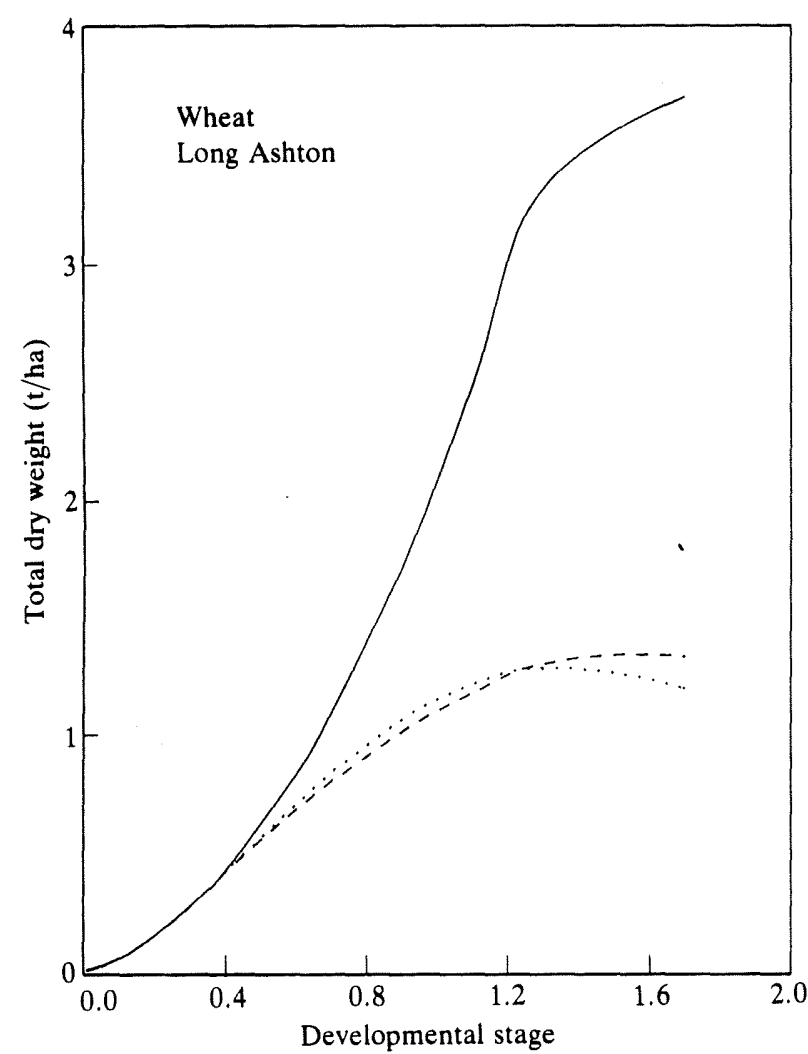

Fig. 8. The effect of winter wheat canopy height on the simulated total dry weight (above-ground) of winter wheat as a function of developmental stage when grown in mixture with Avena fatua at Long Ashton. Observed canopy heights of Avena fatua were input to the model. Winter wheat canopy heights were: (-) observed heights as input; $(\ldots$.$) the relationship shown by the solid line in Fig. 4$ but a maximum canopy height of $0.6 \mathrm{~m}$; and $(---)$ the relationship shown by the dashed line in Fig. 4 . 
At Long Ashton, growth of both species was simulated accurately early in the life cycle, but dry matter accumulation of winter wheat was overestimated for the last two harvests before anthesis, and dry matter growth of $A$. fatua was underestimated (Fig. 7). This was the case both when observed leaf areas were input to the model and when leaf area development was simulated. The growth in canopy height of monocultures of $A$. fatua in this sowing at Long Ashton (maximum height $1.6 \mathrm{~m}$ ) was considerably greater than that observed at Broom's Barn or at five previous sowings at Long Ashton (maximum height $1.1 \mathrm{~m}$, Weaver et al., 1993). Canopy heights in mixture were similar to those in monoculture for both winter wheat and $A$. fatua (data not shown). When observed heights were input to the model, simulated dry matter accumulation of both species agreed more closely with observed values, although leaf area index of $A$. fatua was still overestimated (Fig. 7).

\section{Model analyses}

The relative canopy height of the two species influences the proportion of the incoming radiation that each receives. Sensitivity analyses were performed for the Long Ashton sowing in which: 1) the maximum height of the wheat canopy was decreased from $0.95 \mathrm{~m}$ to $0.6 \mathrm{~m}$, and 2) both the onset and completion of stem extension in winter wheat were delayed by 30 degree days (approximately 3 calendar days) (Fig. 4, dashed line). Observed

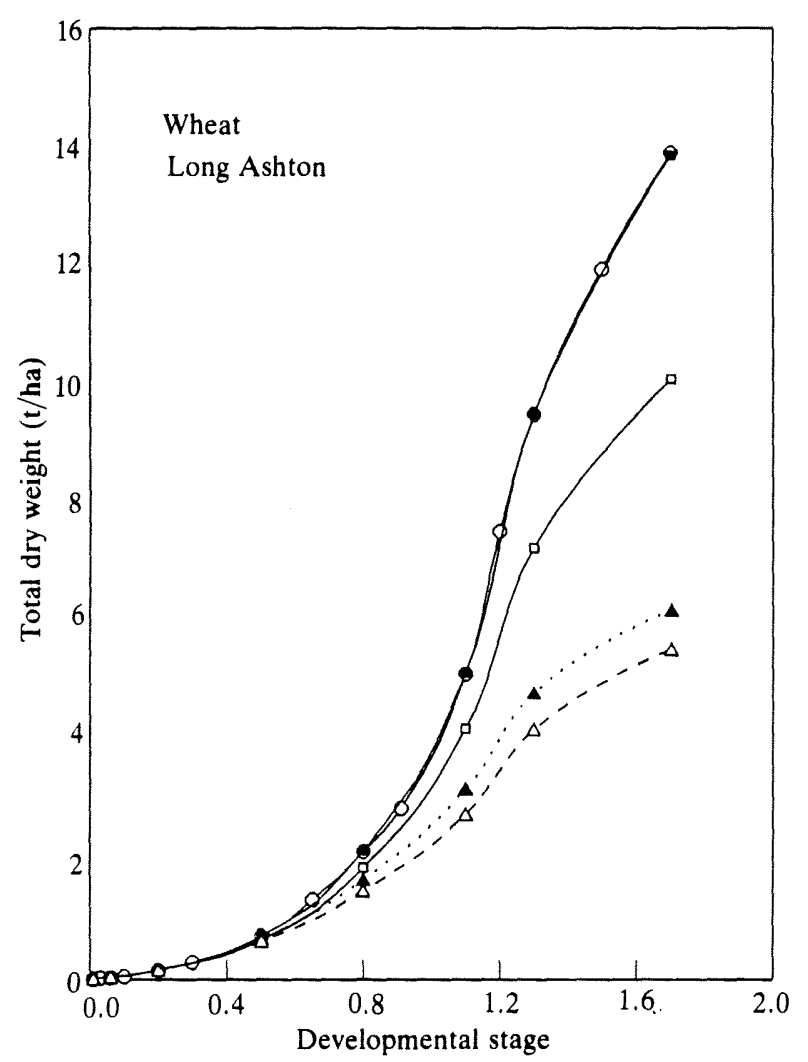

Fig. 9. The effect of date of emergence of Avena fatua on the simulated total dry weight (above-ground) of winter wheat sown on 17 October 1988 at Long Ashton. Dates of Avena fatua emergence were: $\left(--\Delta_{--}\right)$same as wheat; $(\ldots \Delta$. . .) 2 weeks after wheat; $(-\square-) 5$ weeks after wheat; (-口-) early spring. Simulated growth of a monoculture of winter wheat without Avena fatua is also shown (-O-). 
heights of $A$. fatua were used as input in these simulation runs, but all other parameters remained unchanged. When the maximum canopy height of winter wheat was reduced to $0.6 \mathrm{~m}$, or when the onset and completion of stem extension of winter wheat were delayed by only 30 degree days, winter wheat biomass just before anthesis was reduced by approximately $65 \%$ (Fig. 8). Simulated dry matter accumulation of winter wheat was sensitive, therefore, not only to the maximum canopy height achieved by each species, but also to a delay in canopy height growth relative to that of $A$. fatua, as had been suggested by Cousens et al. (1991).

Simulation runs were also conducted varying: 1 ) the time of emergence, and 2) the density of $A$. fatua for the Long Ashton sowing. Simulated times of emergence of $A$. fatua were 2 wk and 5 wk after crop emergence in autumn 1988, and early in March 1989, with all other parameters left unchanged. Simulated $A$. fatua densities were $0,10,50,100,300,500,1000$ and 1500 plants $\mathrm{m}^{-2}$, with a winter wheat density of 300 plants $\mathrm{m}^{-2}$ to allow comparison to published data. Simulated crop yield data as a function of weed density were fitted to the descriptive model of Cousens (1985):

$$
Y_{L} \frac{I d}{(1+I d / A)}
$$

where $Y_{L}$ is percent yield loss, $d$ is weed density, $I$ is the percent yield loss per unit weed density as $\mathrm{d}$ approaches 0 , and $\mathrm{A}$ is the asymptotic yield loss as $\mathrm{d}$ approaches infinity.

Delayed emergence of $A$. fatua resulted in increased biomass accumulation by winter wheat. Winter wheat biomass at anthesis increased by $12 \%$ and $82 \%$, with delays in emergence by $A$. fatua of 2 wk and 5 wk, respectively (Fig. 9). Spring emerging $A$. fatua caused no reduction in winter wheat biomass compared to a weed-free monoculture with the same wheat density. Simulated yields of winter wheat declined as the density of $A$. fatua

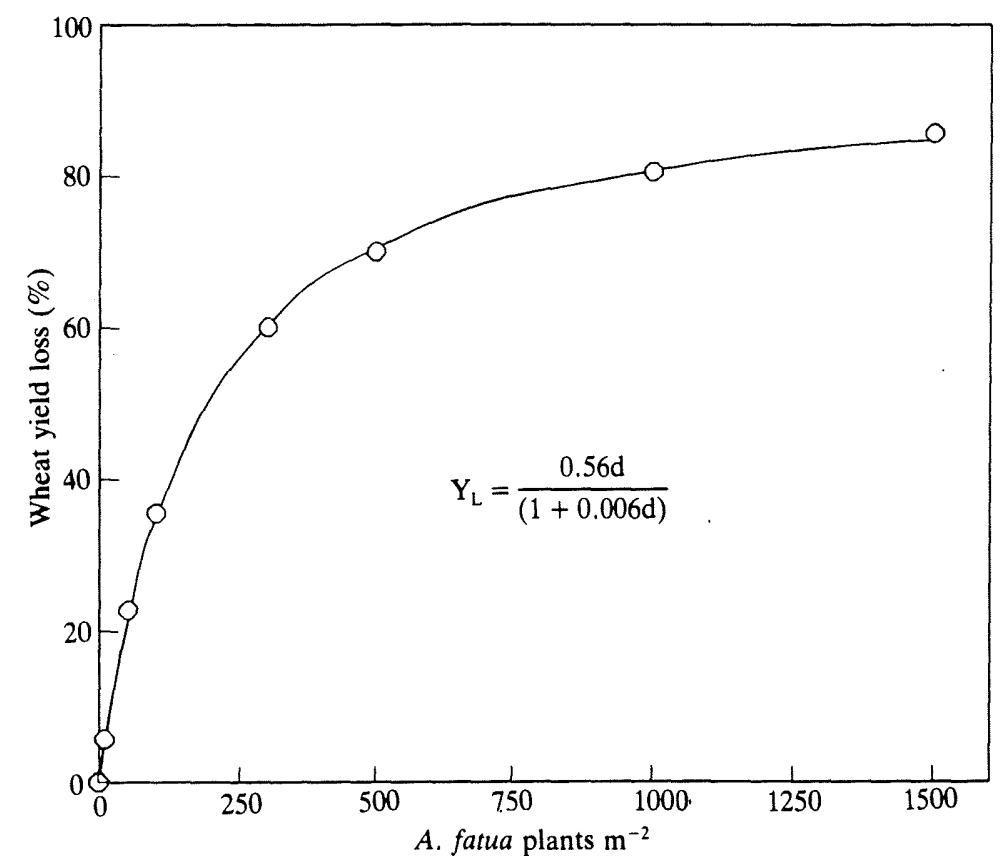

Fig. 10. Simulated yield losses of winter wheat as a function of Avena fatua density. In the simulation runs winter wheat and Avena fatua were sown at Long Ashton on 17 October 1988 with a crop density of 300 plants $\mathrm{m}^{-2}$. Open circles indicate simulated values; the solid line is the fitted curve. 
increased from 0 to 1500 plants $\mathrm{m}^{-2}$ (Fig. 9). Fitting simulated yield losses of winter wheat to the function of Cousens (1985) resulted in parameter estimates of $\mathrm{I}=0.56$ and $\mathrm{A}=$ $94.2 \%$, with an estimated weed-free yield of $8.4 \mathrm{t} \mathrm{ha}^{-1}$ (Fig. 10).

\section{Discussion}

In general, the model was able to accurately simulate the growth of $A$. fatua and winter wheat both in monoculture and in mixture, based on calculations of the amount of light intercepted by each species and known relationships between development, dry matter partitioning, and temperature and photoperiod. Accurate simulations of growth in mixtures depended upon an accurate description of canopy height, which influences the relative share of the incoming radiation that each species receives. Canopy height does not affect simulations in monoculture, because the growth of the population $\left(\mathrm{kg} \mathrm{ha}^{-1}\right)$ rather than of individual plants is modelled, and the horizontal distribution of leaf area is assumed to be homogeneous for each species.

Simulations of growth in mixtures were sensitive to both the maximum height reached by the canopy of each species, and the relative timing of canopy height growth. These sensitivity analyses are supported by experimental work. Several studies have demonstrated that shorter wheat varieties, and particularly dwarf wheats, suffer greater yield losses due to competition from wild oat species than taller varieties (Balyan et al., 1991; Cudney et al., 1991). Thurston (1962) noted that winter cereals strongly suppress the growth of springemerging A. fatua. Other studies have shown that the competitive ability of $A$. fatua is substantially reduced if it emerges 2 to 6 wk later than either spring or winter wheat (Martin \& Field, 1988; O'Donovan et al., 1985). Few studies, however, have examined the effect of variation in canopy height of $A$. fatua on its competitive ability with winter wheat (Rooney, 1991). The reason for the greater height growth of the $A$. fatua monoculture sown at Long Ashton in October 1988, compared to that of monocultures sown on five other dates (Weaver $e t a l ., 1993$ ), is unknown. The canopy of $A$. fatua is generally slightly below or equal to the wheat canopy until just before flag leaf emergence, at which point it begins to overtop the wheat (Cousens et al., 1991; Cudney et al., 1991). The canopy of $A$. fatua continues to rise after wheat stem elongation has ceased, and reduces light penetration to the wheat canopy during floral development (Cudney et al., 1991). In the model, canopy height is an empirical function of developmental stage and the effect of shading on height is not accounted for. In the present study, the relationship between canopy height and developmental stage did not vary between monocultures and mixtures for either winter wheat or A. fatua. Cudney et al. (1991) also reported that the canopy heights of $A$. fatua and spring wheat did not differ between monocultures and mixtures at $A$. fatua densities up to 300 plants $\mathrm{m}^{-2}$. Balyan et al. (1991) found, on the other hand, that the height of a related species, $A$. ludoviciana, varied with the height of the winter wheat cultivar when grown in mixture. Canopy height may also be affected by the availability of water and nutrients (Carlson \& Hill, 1986; Cudney et al., 1991), although these resources were assumed to be adequately supplied in the present study.

Accurate simulation of leaf area index is also more important for modelling the growth of mixtures of plant species, in which the amount and position of leaf area determines the relative amount of light interception, than for monocultures with closed canopies. The model makes the simplifying assumption that the vertical distribution of leaf area is parabolic for both species in monoculture and in mixture throughout the growing season. Cudney et al. (1991) demonstrated that interference between spring wheat and $A$. fatua did not alter the vertical distribution of leaf area, although the shape of the distributions changed from 
pyrimidal at the tillering stage to more parabolic at later growth stages. However, Légère \& Schreiber (1989) and Regnier \& Stoller (1989) reported that the canopy architecture of several dicotyledonous weeds was altered by interference with soybean (Glycine max).

The reason for the model's underestimation of dry matter growth of $A$. fatua in mixture with winter wheat for the two harvests prior to anthesis at both Broom's Barn and Long Ashton is not clear. The model also underestimated growth of monocultures of $A$. fatua for these harvests at the same sites and dates of sowing (Weaver et al., 1993). In contrast, growth of monocultures of $A$. fatua was accurately simulated for five other dates of sowing (Weaver et al., 1993). It is possible that weather conditions during the spring of 1989 altered the partitioning of assimilates to roots and shoots, but this hypothesis could not be tested because root weights were not measured.

The ability of the model to simulate growth of $A$. fatua and winter wheat from anthesis to maturity has yet to be validated because harvests ceased at anthesis. Nevertheless, model predictions of wheat yield losses in relation to $A$. fatua density showed good agreement with published data, despite oversimplification of floral development and the dynamics of the distribution of assimilates to the grains. The estimated parameter values for the function of Cousens (1985) relating crop yield loss to weed density compare favourably to experimental values reported by Cousens et al. (1984) for $A$. fatua in winter wheat under similar environmental conditions $(\mathrm{I}=0.75, \mathrm{~A}=96.7 \%)$. The ability of the model to accurately simulate crop yield losses under more extreme environmental conditions remains to be tested. Furthermore, the morphology and physiology of $A$. fatua are extremely variable throughout its range (Miller, Nalewaja \& Mulder, 1982), and so application of the model to other geographic areas and winter wheat cultivars may require independent derivation of at least some parameter values.

\section{Acknowledgements}

Partial funding of this study by a NATO travel grant is gratefully acknowledged.

\section{References}

Balyan R S, Malik R K, Panwar R S, Singh S. 1991. Competitive ability of winter wheat cultivars with wild oat (Avena ludoviciana). Weed Science 39:154-158.

Carlson H L, Hill J E. 1985. Wild oat (Avena fatua) competition with spring wheat: Plant density effects. Weed Science 33:176-181.

Carlson H L, Hill J E. 1986. Wild oat (Avena fatua) competition with spring wheat. Effects of nitrogen fertilization. Weed Science 34:29-33.

Cousens R. 1985. An empirical model relating crop yield to weed and crop density and a statistical comparison with other models. Journal of Agricultural Science, Cambridge 105:513-521.

Cousens R, Peters N C B, Marshall C J. 1984. Models of yield loss - weed density relationships. 7th International Symposium on Weed Biology, Ecology \& Systematics, pp. 367-374.

Cousens R, Weaver S E, Martin T D, Blair A M, Wilson J. 1991. Dynamics of competition between wild oats (Avena fatua L.) and winter cereals. Weed Research 31:203-210.

Cudney D W, Jordan L S, Hall A E. 1991. Effect of wild oat (Avena fatua) infestations on light interception and growth rate of wheat (Triticum aestivum). Weed Science 39:175-179.

Gallagher J N, Biscoe P V. 1978. Radiation, absorption, growth and yield of cereals. Journal of Agricultural Science, Cambridge 91:47-60.

Graf B, Gutierrez A P, Rakotobe O, Zahner P, Delucchi V. 1990. A simulation model for the dynamics of rice growth and development: Part II - The competition with weeds for nitrogen and light. Agricultural Systems 32:367-392.

van Heemst J D J. 1988. Plant data values required for simple crop growth simulation models: review and bibliography. Simulation Report CABO-TT no. 17, Agricultural University, Wageningen, The Netherlands 
Holm L G, Plucknett D L, Pancho J V, Herberger J P. 1977. The World's Worst Weeds: Distribution and Biology. University Press of Hawaii.

Kropff M J. 1988. Modelling the effects of weeds on crop production. Weed Research 28:465-471.

Kropff M J, Spitters C J T. 1992. An eco-physiological model for interspecific competition, applied to the influence of Chenopodium album $\mathrm{L}$. on sugar beet. I. Model description and parameterization. World Research 32:437-450.

Légère A, Schreiber M M. 1989. Competition and canopy architecture as affected by soybean (Glycine max) row width and density of redroot pigweed (Amaranthus retroflexus). Weed Science 37:84-92.

Martin M P L D, Field R J. 1988. Influence of time of emergence of wild oat on competition with wheat. Weed Research 28:111-116.

Martin R J, Cullis B R, McNamara D W. 1987. Prediction of wheat yield loss due to competition by wild oats (Avena spp.). Australian Journal of Agricultural Research 38:487-499.

Miller S D, Nalewaja J D, Mulder C E C. 1982. Morphological and physiological variation in wild oat. Agronomy Journal 74:771-775.

Morishita D W, Thill D C, Hammel J E. 1991. Wild oat (Avena fatua) and spring barley (Hordeum vulgare) interference in a greenhouse experiment. Weed Science 39:149-153.

O'Donovan J T, de St Remy R A, O'Sullivan P A, Dew D A, Sharma A K. 1985. Influence of relative time of emergence of wild oat (Avena fatua) on yield loss of barley (Hordeum vulgare) and wheat (Triticum aestivum). Weed Science 33:498-503.

Pavlychenko T K, Harrington J G. 1935. Root development of weeds and crops in competition under dry farming. Scientific Agriculture 16:151-160.

Penning de Vries F W T, van Laar H H. (Eds). 1982. Simulation of plant growth and crop production. Pudoc, Wageningen: Simulation Monographs.

Peters N C B, Wilson B J. 1983. Some studies on the competition between Avena fatua L. and spring barley. II. Variation of $A$. fatua emergence and development and its influence on crop yield. Weed Research 23:305-311.

Regnier E E, Stoller E W. 1989. The effect of soybean (Glycine max) interference on the canopy architecture of common cocklebur (Xanthium strumarium), jimsonweed (Datura stramonium), and velvetleaf (Abutilon theophrasti). Weed Science 37:187-195.

Rooney J M. 1991. Influence of growth form of Avena fatua L. on the growth and yield of Triticum aestivum L. Annals of Applied Biology 118:411-416.

Spitters C J T. 1989. Weeds: population dynamics, germination and competition. In Simulation and systems management in crop protection, pp. 182-216. Eds R Rabbinge, S A Ward and H H van Laar. Pudoc, Wageningen: Simulation monographs.

Spitters C J T, Aerts R. 1983. Simulation of competition for light and water in crop weed associations. Aspects of Applied Biology 4 Influence of Environmental Factors on Herbicide Performance and Crop and Weed Biology, pp. 467-484. .

Spitters C J T, van Keulen H, van Kraalingen D W G. 1989. A simple and universal crop growth simulator: SUCROSS87. In Simulation and systems management in crop protection, pp. 147-181. Eds R Rabbinge, S A Ward and H H van Laar. Pudoc, Wageningen: Simulation monographs.

Thurstom J M. 1959. A comparative study of the growth of wild oats (Avena fatua L. and $A$. ludoviciana Dur.) and cultivated cereals with varied nitrogen supply. Annals of Applied Biology 47:716-739.

Thurston J M. 1962. The effect of competition from cereal crops on the germination and growth of Avena fatua L. in a naturally infested field. Weed Research 2:192-207.

Weaver S E, Kropff M J, Cousens R. 1993. A simulation model of Avena fatua L. (wild-oat) growth and development. Annals of Applied Biology 122:537-554.

Weir A H, Bragg P L, Porter J R, Rayner J H. 1984. A winter wheat crop simulation model without water or nutrient limitations. Journal of Agricultural Science, Cambridge 102:371-382.

Wilkerson G G, Jones J W, Coble H D, Gunsolus J L. 1990. SOYWEED: A simulation model of soybean and common cocklebur growth and competition. Agronomy Journal 82:1003-1010.

Wilson B J, Peters N C B. 1982. Some studies of competition between Avena fatua L. and spring barley. I. The influence of $A$. fatua on yield of barley. Weed Science 22:143-148.

(Received 29 April 1993) 